\title{
Discutindo o Gênero Webcomic: O Papel da Avaliatividade no Multiletramento Crítico em Língua Inglesa.
}

\author{
Rodrigo Costa dos Santos \\ Pontifícia Universidade Católica do Rio de Janeiro - PUC-Rio
}

\begin{abstract}
Resumo
A fim de contribuir aos estudos em multiletramento crítico em língua inglesa, "requerido para o trato ético dos discursos em uma sociedade saturada de textos" (ROJO, 2009), e no contexto da cibercultura (LÉVY, 2010), o presente trabalho busca investigar as práticas de multiletramento a partir da análise da discussão online feita por alunos em um curso de língua inglesa. Para isso, baseia-se na concepção sociossemiótica de linguagem, de acordo com a Linguística SistêmicoFuncional (HALLIDAY;MATHISESSEN, 2014). A análise é feita a partir do Sistema de Avaliatividade (MARTIN;WHITE, 2005) e a metodologia de pesquisa se alinha com o paradigma qualitativo (DENZIN;LINCOLN, 2005). O corpus consiste nas discussões no grupo on-line do Facebook propostas a partir da leitura de dois webcomics disponíveis nos sites http://www.smbc-comics.com, e http://www.asofterworld.com.
\end{abstract}

Palavras-chave: Webcomics. Multiletramento. Língua Inglesa. Facebook. Cibercultura

\begin{abstract}
In order to contribute to critical multiliteracy studies in English, "required for the ethical treatment of discourses in a society saturated with texts" (ROJO, 2009), and in the context of cyberculture (LÉVY, 2010), the present work aims to investigate multiliteracy practices on-line through the analysis of on-line discussion produced by students in an English language course. To this end, our study is based on the socio-semiotic conception of language, according to Systemic-Functional Linguistics (HALLIDAY;MATHISESSEN, 2014). The analysis is grounded in the Appraisal System (MARTIN;WHITE, 2005), and the research methodology is aligned with the qualitative paradigm (DENZIN;LINCOLN, 2005). The corpus consists of discussions in the Facebook group proposed from the reading of two webcomics available on the http://www.smbc-comics.com and http://www.asofterworld.com websites.

Keywords: Webcomics. Multiliteracies. English language. Facebook. Cyberculture
\end{abstract}

\section{INTRODUÇÃO}

A interação pela internet provocou uma enorme mudança nos modos de leitura e escrita. O hipertexto causou uma quebra no paradigma grafocêntrico de comunicação, na qual a escrita da mídia impressa passou a se relacionar de forma fluída com a escrita hipermidiática (SIGNORINI, 2013). Esse novo paradigma exige que se ensine novos letramentos e que se 
pense na forma como os mesmos podem afetar o ensino-aprendizagem, visto que a proficiência em línguas só se desenvolve a partir de seu uso em situações significativas nas quais os estudantes possam expressar suas ideias e questionamentos (PINTO, 2010).

O estudo dos multiletramentos se torna cada vez mais importante à medida que ele é requerido para o trato ético dos discursos em uma sociedade semioticamente saturada (ROJO, 2009) e mergulhada nos múltiplos dilúvios da cibercultura (LÉVY, 2010). Do computador de mesa ao smartphone, estamos cada vez mais imersos nas mídias digitais e no enorme fluxo de informação que advém da recente revolução nas telecomunicações.

Por esse motivo, o objetivo do presente trabalho é a busca por entendimentos em relação aos discursos (co)construídos na interação em ambientes on-line por meio da análise de um grupo de Facebook integrado por alunos de um curso de língua inglesa em Niterói, Rio de Janeiro.

Para cumprir os objetivos mencionados, baseio-me na concepção sociossemiótica de linguagem, que entende o texto como uma unidade semântica, de acordo com a teoria da Linguística Sistêmico-Funcional (HALLIDAY \& MATHISESSEN, 2014). Além da teoria teleológica de Martin (1992), que compreende que o gênero (contexto de cultura) precede o registro (contexto de situação) e é responsável pela integração de suas variáveis (campo, relações e modo). Também são consideradas as contribuições de Rojo (2009) para o estudo do letramento protagonista, focado em compreender formas de ensino do trato ético nas práticas de leitura e escrita.

A análise é feita a partir do Sistema de Avaliatividade (MARTIN;WHITE, 2005; VIAN JR, 2010), focando-se na Atitude (Afeto, Julgamento e Apreciação) do aluno ao se posicionar nas discussões. Para tal, faço as seguintes perguntas de pesquisa: que Atitudes os alunos apresentam na interação on-line? Como essas atitudes influenciam sua interação online? O quanto seus níveis de (multi)letramento afetam a interação?

A metodologia de pesquisa se alinha com o paradigma qualitativo-interpretativista (DENZIN; LINCOLN, 2005) e o corpus consiste nas discussões tecidas com os alunos no grupo on-line do Facebook propostas a partir da leitura de dois webcomics em inglês disponíveis nos sites Saturday Morning Breakfast Cereal (http://www.smbc-comics.com), e A Softer World (http://www.asofterworld.com), respectivamente. 


\title{
FUNDAMENTAÇÃO TEÓRICA
}

\section{Linguística Sistêmico Funcional e Linguística Aplicada}

A Linguística Aplicada no Brasil é marcada por um foco inicial nos estudos contrastivos e ensino de língua inglesa (CAVALCANTI, 2004) e subsequente mudanças que geraram as linguísticas crítica e indisciplinar (VIAN JR, 2013). É nessa última que entendo que a Linguística Sistêmico Funcional (doravante LSF) se insere por excelência, devido à sua origem transdisciplinar e sua inserção em diversos campos da Linguística Aplicada.

Os estudos em análise crítica de discurso, focados na prática discursiva e nas relações de poder construídas através da linguagem, são influenciados pela LSF, pois "Halliday não concebe a gramática de maneira estruturalista, imanentista, o que justifica a escolha de Fairclough pela gramática sistêmico-funcional.”(OLIVEIRA; CARVALHO, 2013)

No ramo dos estudos em multimodalidade, destacam-se os estudos de Sônia Pimenta, da UFMG, sobre as práticas semióticas. A grande base para os estudos semióticos no Brasil foi a Gramática do Design Visual de Kress e van Leeuwen (1996) que, por sua vez, foram grandemente influenciados pela LSF, como destacam Meuer e Balocco:

\begin{abstract}
A gramática visual de Kress e van Leeuwen compartilha com a LSF os seguintes pressupostos teóricos: 1) a visão dos sistemas semióticos como repertórios semânticos a partir dos quais podem ser feitas escolhas, motivadas pelas características de uma situação concreta de comunicação e do contexto de cultura; 2) a visão dos sistemas semióticos como suportes para a interação social; 3) a visão da funcionalidade dos sistemas semióticos, que se organizam em torno de três metafunções: a ideacional, a interpessoal e a textual (MEUER; BALOCCO, 2009, p. 5)
\end{abstract}

Vian Jr segue ao destacar a LSF como um campo de estudo pluridisciplinar e diversificado (p. 131): “A LSF insere-se no Brasil já com um caráter eminentemente interdisciplinar, uma vez que passa a fazer parte dos trabalhos que estudam diversos aspectos da linguagem em uso e, da mesma forma, auxilia na descrição de aspectos tipológicos da língua portuguesa."

Para entender o fenômeno do discurso pela lente da LSF, dois conceitos são necessários: estratificação e metafunção. Estratificação compreende o modo como o discurso se manifesta na língua e na linguagem: através dos estratos da cultura, do texto e da gramática. Esses estratos se relacionam por meio do que a LSF descreve como realização: A cultura é realizada como textos, que por sua vez são realizados como orações. Um exemplo da 
estratificação é dado por Martin e White (2003) ao contar a história de Helena, uma mulher sul-africana que viveu durante o apartheid.

Helena escreveu uma carta a uma estação de rádio narrando sua história. A estratificação ocorre, como os autores apontam:

Cultura: a luta por justiça na África do Sul

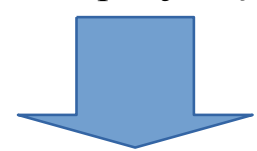

Texto: a história de injustiça de Helena

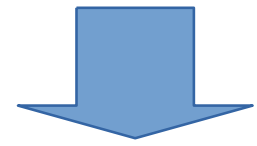

Gramática: Helena no tempo e no espaço. Por exemplo: "Minha história começa no fim da minha adolescência, quando era uma garota da fazenda no distrito de Bethelem..." (Adaptado de MARTIN;WHITE, 2003, p. 2)

O segundo conceito necessário à compreensão da LSF é a metafunção. A partir do conceito de metafunção, a linguagem é organizada em três funções sociais gerais: representar nossas experiências, estabelecer nossos relacionamentos sociais e organizar essas representações e relacionamentos como textos com significado (MARTIN; ROSE, 2003, p. 7). Essas são as metafunções da linguagem como propostas pelo modelo da LSF. A metafunção ideacional para representar a experiência, a interpessoal para estabelecer os relaciomentos e a textual para organizar o texto. Essas três metafunções se interrelacionam durante a atividade social e são responsáveis pela construção do discurso.

As metafunções ideacional, interpessoal e textual ${ }^{1}$, propostas por Halliday ([1985]2014) foram aplicadas a diferentes contextos de análise linguística como, por exemplo, os Sistemas Discursivos elaborados por Martin e Rose (2003). O Sistema de Avaliatividade foi concebido inicialmente por Martin e White a partir dos Sistemas Discursivos com o objetivo de desenvolver um modelo análise do significado interpessoal que pudesse dar conta de observar o afeto somado às categorias de modalidade e modo da LSF² (MARTIN;WHITE, 2005).

Esse ferramental de análise é útil ao buscar a compreensão dos significados interpessoais "[a]o considerarmos as formas como ocorrem os mecanismos de avaliação do

1 cf Halliday, 2014, p. 30-31

2 cf. Halliday, 2014, p.134-200 
ponto de vista de sua realização léxico-gramatical, temos uma vasta gama de escolhas disponíveis no sistema linguístico.” (VIAN JR., 2010)

O sistema desenvolvido por Martin e White, que busca analisar os recursos utilizados na interação para avaliar algo quando (co)construímos significados, utiliza as categorias de Atitude, Gradação e Engajamento. Essas categorias são responsáveis por compreender as maneiras, o grau e o nível de compromisso que expressamos, respectivamente, em nossa avaliação.

As Atitudes mostram como o falante/escritor avalia os participantes envolvidos na interação de forma implícita ou explicita, através do Afeto, Julgamento e a Apreciação. O subsistema de Engajamento é utilizado para analisar a forma o quanto a voz autoral se compromete com o que diz, enquanto o subsistema de Gradação é utilizado em conjunção com os subsistemas anteriores modificando (por atenuação ou realce) os sentidos construídos naqueles subsistemas.

Vian Jr (2010, p. 20) destaca a importância das "atitudes, [que] a partir da perspectiva do Sistema da Avaliatividade, podem ainda ser vistas como um sistema da semântica discursiva, que se realiza léxico-gramaticalmente por meio de diferentes estruturas gramaticais."

No subsistema das Atitudes, o Afeto, usado para expressar nossas emoções e sentimentos, é geralmente direcionado às pessoas. Pode ser a expressão de bons ou maus sentimentos, de forma direta ou implícita (MARTIN; ROSE, 2003, p. 29). O Julgamento, que é também direcionado geralmente às pessoas, é uma forma de expressar a avaliação do caráter. Esses julgamentos podem ser pessoais (admiração ou criticismo) ou morais (louvor ou condenação). A Apreciação, diferentemente do Afeto e do Julgamento, é geralmente direcionada às coisas, à arte (como a pintura), e aos fenômenos da natureza (como o céu estrelado à noite). Como as duas categorias anteriores, a Apreciação pode ser positiva e negativa.

A pesquisa em Avaliatividade e ensino é focada, entre outras aplicações, no entendimento do uso dos recursos de Afeto na argumentação em gêneros jornalísticos (LIMA;COROA, 2010), no domínio científico (MOTTA-ROTH;LOVATO, 2011), e na coconstrução de identidades na prática escrita em sala de aula (NÓBREGA;ABREU, 2015).

No presente trabalho, os recursos de Afeto, Julgamento e Apreciação são úteis para compreender a maneira que os alunos interagem (avaliam) os discursos com quais têm contato por meio dos gêneros que utilizam para interagirem on-line. Ciente de que existem diferenças 
na constituição dos gêneros on-line em relação aos off-line, tratarei das características dos gêneros on-line na próxima seção.

\section{Multiletramento(s) e Hipertexto}

O cenário criado pela globalização tem causado diversas mudanças de paradigma nas comunicações e na interação social. Por isso, autores como Kumaravadivelu tem trazido para o campo de estudo da Linguística o conceito de globalização em seus aspectos econômico e cultural e suas implicações para o fazer Linguística Aplicada na contemporaneidade. Porém, julgo ser necessário à discussão compreender também como caracterizar o ciberespaço - o ambiente virtual no qual construímos significados - e o hipertexto, a unidade semântica que torna possível essas interações sociais.

O termo ciberespaço aparece pela primeira vez no romance de William Gibson Neuromancer (1984) para descrever o espaço das redes digitais, um campo de relações sociais e culturais marcado pelos conflitos que emergem das novas fronteiras criadas por aquele espaço. Para Lévy (1999, p. 94), foi na apropriação desse termo pelas diversas correntes artísticas e sociais que nos inserimos na "cibercultura".

O autor define, dessa forma, o ciberespaço "como o espaço de comunicação aberto pela interconexão mundial dos computadores e das memórias dos computadores. Essa definição inclui o conjunto dos sistemas de comunicação eletrônica [...], na medida em que transmitem informações provenientes de fontes digitais ou destinadas à digitalização." (LÉVY, 1999, p. 94-95). Uma vez digitalizados os dados se tornam virtuais, ou seja, capazes de serem compartilhados e transformados no ciberespaço.

Entretanto, o termo "virtual" não implica o oposto de "real", como se não tivesse existência. Martino salienta que Lévy defende a ideia de que o "virtual" é parte integrante do real e não se opõe a ele:

No ciberespaço todas as informações e dados existem, mas não são acessados ao mesmo tempo. Estão lá, nas memórias de computadores e servidores. Existem como algo que pode ser, algo virtual, e vão se tornar um ato quando forem acessados e se transformarem em figuras, imagens, textos e sons na tela. Os dados do ciberespaço são todos virtuais até que se transformem naquilo que devem ser. (MARTINO, 2015, p. 30)

Assim, o espaço virtual ou ciberespaço deve ser entendido não como caracterizado pelo oposto ao real, mas como oposto ao atual, em outras palavras, um espaço no qual a informação é algo que não está acontecendo neste momento. O mundo virtual, portanto, "existe enquanto possibilidade, e se torna visível quando acessado, o que não significa que não seja real." (MARTINO, 2015, p. 31). Essa característica do ciberespaço traz à tona 
questões relativas à interação mediada pela linguagem que, anteriormente regulada pelos princípios que regem a mídia impressa (como a linearidade), se defronta com o hipertexto, modo de organização da linguagem na internet.

Hipertexto é definido por Xavier (2010, p. 208) como "uma forma híbrida, dinâmica e flexível de linguagem que dialoga com outras interfaces semióticas, adiciona e acondiciona à sua superfície formas outras de textualidade.” Ele é, portanto, um reflexo das relações criadas pelo ciberespaço ao realizar-se a partir das ligações (links) em páginas da internet, se organizando de forma a desafiar a linearidade característica dos textos da chamada Old Media.

Isso gera um desafio quanto ao modo que lemos na internet. $\mathrm{O}$ caráter não-linear faz com que tenhamos que repensar a forma como a leitura hipertextual transforma nossas relações e muda a dinâmica das relações interpessoais. Xavier reforça que a inovação trazida pelo hipertexto "está em transformar a deslinearização, a ausência de um foco dominante de leitura, em princípio básico de sua construção.” (2010, p. 213)

Essas mudanças nas relações de leitura e escrita fazem com que se deva estudar essas novas formas de letramento e como ensinar o aluno a lidar com essa mudança de paradigma que marca a Era da Informação. Em seguida, faço uma breve exposição dos estudos em (multi)letramento e como eles se inserem no presente trabalho.

Os estudos de letramento são essencialmente divididos em dois grandes grupos: um que trabalha com uma visão não social de linguagem, concebendo o letramento como uma série de habilidades de leitura e escrita autônomas e descontextualizadas, focadas no indivíduo; e outro que, por sua vez, se alinha com uma visão de letramento como um grupo de práticas socioculturalmente situadas e ideologicamente construídas (FIGUEIREDO, 2014).

Nessa segunda corrente, o New London Group (fundado em 1994), se destaca por suas contribuições ao estudo de letramentos como prática social, entendendo "[...]a mudança de palavras e as novas demandas que são colocadas sobre as pessoas como criadores de significado na mudança de locais de trabalho, como cidadãos em espaços públicos em mudança e nas dimensões mutáveis da nossa vida comunitária[...]”3 (COPE;KALANTZIS, 2000, p. 4)

Figueiredo (2014, p. 146) sinaliza a dificuldade em definir letramento, pois, dependendo do ponto de vista, o termo pode ter diferentes significados e traz dois questionamentos de Britto (2004, p. 52): o quanto (e como) essas habilidades de leitura e

3 Tradução minha. "the changing word and the new demands being placed upon people as makers of meaning in changing workplaces, as citizens in changing public spaces and in the changing dimensions of our community lives.". 
escrita contribuem para que os sujeitos participem e usufruam da produção material e cultural da sociedade em que vivem? Qual a distinção entre as dimensões individuais e coletivas de letramento?

Essas questões podem ser desenvolvidas por meio das reflexões de Rojo (2009, p. 107) que, entendendo o letramento como um conjunto de práticas sociais, defende a escola como principal agência de letramento: "Um dos objetivos principais da escola é justamente possibilitar que seus alunos possam participar das várias práticas sociais que se utilizam da leitura da escrita (letramentos) na vida da cidade, de maneira ética, crítica e democrática."

Essa concepção, entretanto, assume o letramento como algo que deve ser ensinado ao aluno em vez de ser desenvolvido nas suas interações sociais no ambiente escolar. Defendo que o aluno possua senso crítico, uma autonomia que deve ser respeitada, como adverte Freire (2011, p. 58): “O respeito à autonomia e à dignidade de cada um é um imperativo ético e não um favor que podemos ou não conceder uns aos outros."

Uma concepção de letramento que considere a individualidade do aluno como ser pensante se torna cada vez mais necessária ao lidarmos com a mudança de paradigma que advém da chamada pós-modernidade. Moita Lopes (2012, p. 154, apud Figueiredo, 2014.) defende que a escola precisa dialogar com o novo ethos ${ }^{4}$ ligado às práticas de letramento digital, que permitem a participação em discursos contraditórios, questionadores e inovadores, por seu caráter colaborativo realizado pela escrita hipermidiática.

Escrita hipermidiática são aquelas que se articulam por meio dos princípios da mídia eletrônica, ou seja, "programas computacionais de modo geral, as estruturas hipertextuais, as interfaces gráficas, além das mensagens síncronas e assíncronas produzidas em diferentes ambientes e plataformas digitais." (MANOVICH, 2001). São escritas "constituída[s] de 'camadas' sucessivas de texto que devem fazer a transição entre os códigos ilegíveis da máquina e as linguagens socializadas do homem" (SOUCHIER, 2003, p. 3, apud SIGNORINI, 2013).

É nesse contexto que tento compreender a internet e os diálogos e interações nas quais acontecem as práticas sociais chamadas (multi)letramentos digitais: um contexto de hiperrealidade (BAUDRILLARD, 1985;1995, apud Figueiredo, 2014), que Signorini (2013, p. 209) considera como um apagamento das fronteiras (linha nítida de marcação entre domínios) e o estabelecimento de bordas (espaço comum e fluido entre domínios), para descrever as

4 Como ethos entendo "modos de agir na construção de significados que incluem possibilidades de performances identitárias, modos locucionais que compartilham, e os modos de ser que possibilitam" (MOITA LOPES, 2012, p. 211) 
relações que se estão construindo nas práticas sociais contemporâneas entre escritas grafocêntricas e hipermidiáticas.

\section{O Gênero Webcomic}

A pesquisa em gêneros tem avançado nos últimos trinta anos de forma a expandir a maneira como os utilizamos para (inter)agir socialmente, relacionando diversas variedades de (hiper)textos com diversas formas de ação social (BARWASHI; REIFF, 2013). Essa relação faz com que possamos encarar os gêneros da internet como um meio de entender como interagimos no ciberespaço. Hyon (1996) destaca três tradições de pesquisa em estudos de gêneros que focam no ensino de Língua Inglesa:

English for Specific Purposes (ESP) ou Inglês para Fins Específicos: Caracterizada pelo foco nas características formais do gênero com o objetivo de ensinar aos falantes de línguas estrangeiras inseridos em contextos acadêmicos e profissionais as variedades oral e escrita da língua inglesa.

New Rhetoric Studies ou Nova Retórica: Focada no contexto situacional em que o gênero se realiza com ênfase em compreender propósito (ou ação) social, essa tradição objetiva descrever gêneros acadêmicos escritos em Inglês L1.

Australian Genre Theories ou Teorias Australianas de Gêneros: Fundada nos princípios da Linguística Sistêmico Funcional de Michael Halliday, que foca na relação entre linguagem e suas funções em ambientes sociais. Focada em entender a relação entre forma, função e contexto social, a LSF estuda gêneros em contextos não-profissionais.

A Linguística Sistemico Funcional contribui ao entendimento das relações hipersemiotizadas e possui tradição fundamentada no estudo de gêneros não-profissionais, útil ao entendimento das transformações genéricas que emergiram da internet. Tais transformações são apontadas por Marchuschi (2010), que chama atenção aos gêneros emergentes e como eles afetam as relações on-line:

\footnotetext{
Em certos casos, esses gêneros emergentes [como por exemplo, o e-mail, o chat e a videoconferência] parecem projeções ou 'transmutações' de outros como suas contrapartes prévias, o que sugere a pergunta de se os designers de software seguiram padrões preexistentes como base para moldagem de seus programas. Como novos gêneros só são possíveis dentro de determinados programas, parece a resposta deve ser sim. (MARCHUSCHI 2010, p. 35)
}

Alguns gêneros on-line são recontextualizações de gêneros off-line. Isso chama atenção para a hiper-realidade apontada por Baudrillard: o on-line e o off-line não são mutuamente excludentes e sim um contínuo, separados por uma borda e não por uma fronteira. 
Os avanços da tecnologia da informação e dos recursos de hardware e software junto ao ethos colaborativo da internet causaram diversas mudanças na maneira como se faz arte. Ilustração, edição de imagens e vídeos, entre outras habilidades têm se tornado cada vez mais acessíveis e as pessoas têm criado e transformado cada vez mais os gêneros que emergem em contextos on-line e off-line.

O gênero de quadrinho digital (webcomic) foi um dos gêneros criados e transformados por esse novo paradigma. Esse gênero, modificado pela dinâmica do ciberespaço, mostra-se uma porta para interação na internet e contribui para a inclusão no meio digital. $\mathrm{O}$ webcomic atrai quadrinistas com interesse em ter uma liberdade criativa e um espaço para exercer tal liberdade que a internet pode prover. Como explica McCloud (2006, p. 223):

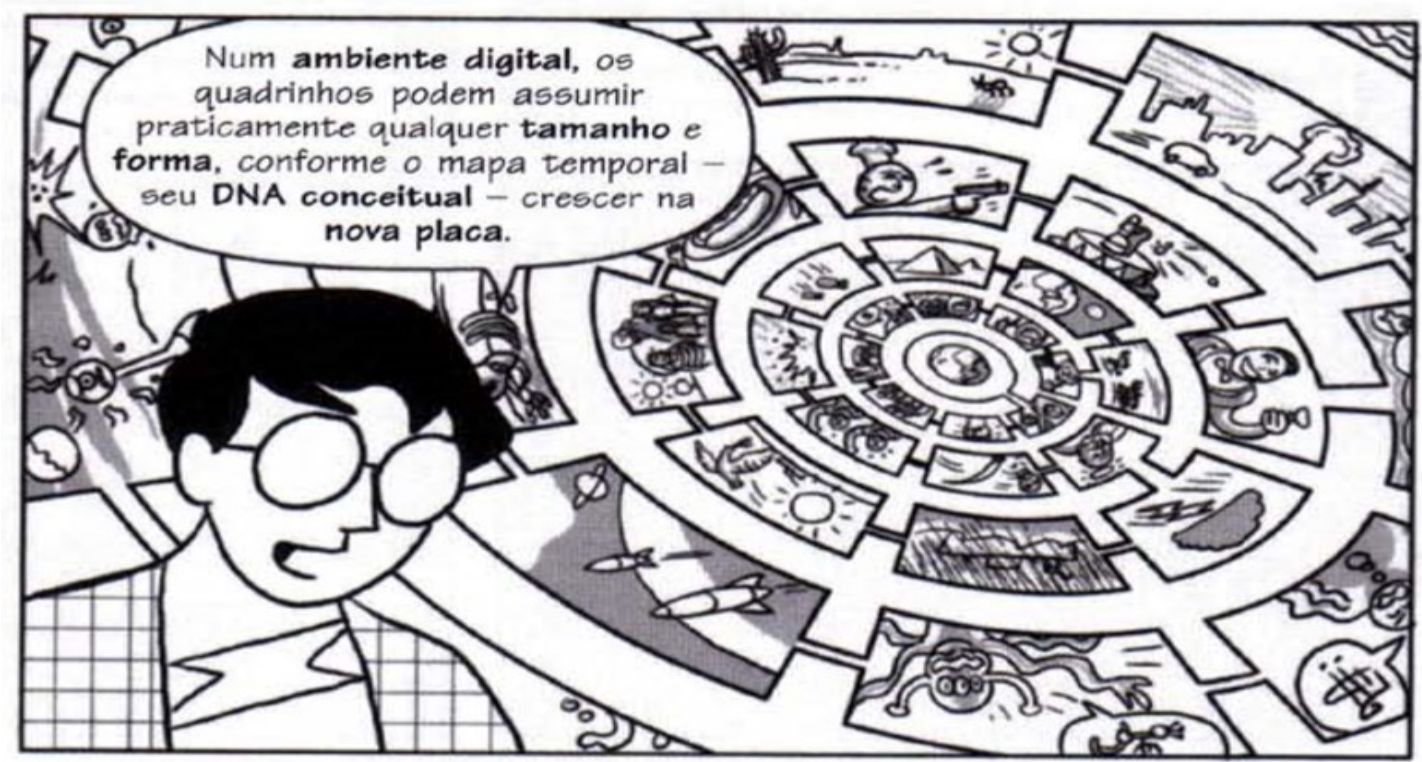

Mendonça (2010) ressalta a importância do uso dos quadrinhos como facilitador do aprendizado. Para a autora "Isso se deve, numa primeira análise, ao papel dos desenhos: (a) 'concretizar' sequências de ações a serem executadas pelo leitor (no caso de instruções); (b) exercer um forte apelo visual (no caso de campanhas publicitárias); (c) atingir largas parcelas populacionais, com diferentes graus de letramento.” (MENDONÇA, 2010, p. 221)

O gênero quadrinhos, assim, provê uma forma de trabalhar os diferentes tipos textuais e situações de interação a partir de uma leitura mais atrativa ao aluno e que, ao mesmo tempo, pode ser explorada como qualquer outro gênero, atentando-se ao seu funcionamento, como explica Mendonça (2010): “Os desenhos associados à sequência narrativa funcionam como recursos didáticos poderosos, tornando tanto mais acessíveis quanto mais 'palatáveis' tópicos 
complexos, com os quais os professores têm dificuldade na prática docente" (MENDONÇA, 2010:223)

\section{METODOLOGIA E ANÁLISE DOS DADOS}

\section{A Metodologia de Pesquisa}

A pesquisa realizada aqui se caracteriza por sua natureza qualitativa e interpretativa, que consiste em um método de caráter exploratório, utilizado quando se necessita "identificar a proporção, grau ou intensidade de um determinado fenômeno" (LEITE, 2015). Por meio dessa metodologia busco contribuir ao estudo crítico das práticas sociais contemporâneas entendendo a internet como um local de interação social caracterizado pela hiper-realidade e passível de uma abordagem de estudo na qual o contexto ganha destaque ao invés das quantificações reducionistas.

Como salienta Leite (2015, p. 100), “'[p]esquisas que se apoiam em números correm o risco de se firmarem na exatidão fria da falta de contexto. Ao contrário, o método qualitativo [...] utiliza de maneira mais adequada os valores culturais e a capacidade de reflexão do indivíduo."

A adoção de um método de pesquisa focado em analisar o contexto da interação contribui ao entendimento da internet (e de sua relação com os espaços sociais off-line) por seu caráter complexo como meio de comunicação, rede de comunicação global e cena de construção social (MARKHAM, 2004). Por isso considerei, nessa pesquisa, as contribuições de meus alunos em um grupo de discussão no Facebook criado por eles.

\section{Contexto da Pesquisa}

Realizei a pesquisa como professor de língua inglesa em um curso localizado em Niterói, RJ. O curso de línguas está inserido em uma universidade carioca que oferece o espaço para realização das atividades. São oferecidos cursos de língua inglesa, francesa, alemã, espanhola, russa e português para estrangeiros, além de Libras (Língua Brasileira de Sinais), Latim e Esperanto.

O grupo de alunos que participou da pesquisa consiste em dez adultos com idades entre 24 e 45 anos, inseridos em diferentes contextos profissionais e acadêmicos. Cinco dos alunos (um deles intercambista vindo do Peru) são universitários graduando em cursos como medicina, artes e sociologia. Outros cinco são profissionais que atuam em áreas como comunicação e direito. 
O trabalho é motivado pela minha percepção, ao conversar com os alunos, de que a produção escrita (redação) que eles faziam era descontextualizada. Na redação, os alunos produzem um texto a partir do conteúdo desenvolvido no livro didático. Não há, porém, um trabalho com o gênero, nem uma discussão prévia sobre a temática que precisam abordar.

As atividades foram conduzidas durante o segundo semestre de 2016 nos meses de setembro e outubro. Criamos um grupo no Facebook para discussão dos temas tratados na unidade por meio da leitura e interpretação de webcomics ${ }^{5}$. O debate foi dado como uma atividade opcional, pois compreendi que não deveria forçar os alunos a participar. Assim, apenas cinco dos dez alunos participaram da conversa no grupo on-line. Quando perguntados, os alunos alegaram falta de tempo para se dedicar à atividade extra.

A primeira questão postada foi relativa à webcomic A Softer World. Nela, perguntei: "What do you think the story is about? Do you think the message of the story is positive or negative? Why?" A segunda postagem, sobre a webcomic Saturday Morning Breakfast Cereal, incluiu as questões: "Do you use Facebook to make arrangements, like Lily and Ben from lesson 3B? Imagine that you can send a message to you from the past telling him/her to travel to a place you want. What message are you sending to him/her? Why?

Na próxima seção, faço a análise da produção dos alunos no grupo on-line e o que essa produção pode nos dizer sobre o letramento em ambientes on-line.

\section{ANÁLISE DOS DADOS}

A discussão (Tabela 1) se inicia com um Julgamento de Estima Social por parte de Alun@ 1, que critica o comportamento da pessoa na história, dizendo que a mesma estaria fantasiando sobre sua tragédia. Alun@1 escolhe o uso do modal "think” (acho), modalizando (Halliday, 2014), ou seja, ressaltando que é uma opinião. Além disso, há a escolha do verbo "overcome" (superar, linha 2), que denota uma crítica ao posicionamento da pessoa representada na webcomic.

5 Os exemplares utilizados na realização da atividade podem ser vistos nos Anexos 1 e 2. 
Tabela 1: Respostas à discussão online

\begin{tabular}{|c|c|}
\hline Linha & Alun@1 1 \\
\hline 1 & Hello people! I think that this story is about a trauma. The man lost his family to the fire, \\
\hline 2 & but he couldn't overcome. So, he created the fantasy for overcome his fear to stay alone. \\
\hline 3 & The menssage of the story is negative for me, because shouldn't run away from problems \\
\hline \multirow[t]{2}{*}{4} & with fantasies. \\
\hline & Alun@2 2 \\
\hline 5 & I think the man wasn't fantasizing to feel good. He was really well so he was smiling. One \\
\hline 6 & day, after many weeks he learns that could fly, mean that he could return his life to normal \\
\hline 7 & because he felt comforted I think this story is positive because I can comfort me, so the \\
\hline \multirow[t]{2}{*}{8} & sadness isn't eternal. \\
\hline & Alun@ 3 \\
\hline 9 & Hello there! For me, this pic is an exemplo about extreme histories that can happens with \\
\hline 10 & some person: any time your life can change totally and you couldn't to do nothing about \\
\hline 11 & that. We are living a perpective of a normal life, and we are not prepared for large \\
\hline 12 & changes. This picture couldn't find answer, it's just to put us in front of one situation in \\
\hline 13 & which we are don't thinking about, but is a possibility, for all us. So, this isn't a history \\
\hline 14 & where we can find positive or negative things. Why? Because I don't know why I living, but \\
\hline \multirow[t]{2}{*}{15} & $\begin{array}{l}\text { I living, and the things. strangers and horrible things, yes, they can be/happen at any } \\
\text { time. }\end{array}$ \\
\hline & Professor \\
\hline 16 & Hello, I like to see all the comments. So, we are talking about how people cope with \\
\hline 17 & tragedy. It is positive if you consider it a message of hope, negative if you see it as fantasy \\
\hline 18 & and none if you see it as they way things are. However, even though it can feel like a \\
\hline 19 & delusion, it is a way to live your life. Right? \\
\hline
\end{tabular}

Entretanto, Alun@s 4 e 5 discordam de Alun@1 ao Avaliar, por meio do Afeto positivo, a Atitude do personagem apresentado na história, interpretando a mensagem como sendo "hope" (esperança, linha 21). Essa interpretação é defendida por meio de uma Apreciação positiva do texto e sua mensagem de esperança ("There's always one day after the other :)", linha 26) ao mesmo tempo que aprecia negativamente a experiência da perda ("The character had a large and significant loss"). 


\begin{tabular}{|l|l|}
\hline & Alun@ 4 \\
\hline 20 & Yes each person reacts in a way about the events of life, I am always very optimistic! !) \\
\hline & Alun@ 2 \\
\hline 21 & Right but I'm a positive person and I can see a mensagem of Hope. \\
\hline & Alun@ 4 \\
\hline 22 & The character had a very large and significant loss, family. This text is that we can resurge \\
23 & from the shadows and there is always a new day. He spent weeks thinking sad about the \\
24 & loss until one day woke up and decided to turn the page, fly to start a new life. The \\
25 & message is for all of us, we often run into difficulties before achieving our dreams and \\
26 & goals. There is always one day after the other.: \\
\hline & Alun@ 5 \\
\hline 27 & I loved the comic strip, because it is an optimistic point of view. Being a comic strip I see it \\
28 & as a means of spreading a metaphor. I do not believe that in fact this man believes it can \\
29 & "fly" because the image he is running, open arms, like wings, but the feet are on the floor \\
30 & If the purpose of the story was to show the perspective of someone who suffers fantasize \\
31 & your life to get out of reality believe it would be represented otherwise. All we live, what we \\
32 & feel, everything we create. Being positive is the best option. \\
\hline
\end{tabular}

Alun@2 discorda do posicionamento de Alun@1, porém sem uma crítica à opinião oposta, denotando um movimento de modulação pela falta de um termo explícito para efetivar a crítica (como dizia Wittgenstein, "Sobre aquilo que alguém não consegue falar, deve-se permanecer em silêncio" ${ }^{\prime}$ ) e também demonstra Afeto positivo em relação a história ao dizer "I can comfort me, so the sadness isn't eternal." (Eu posso me confortar, pois tristeza não é eterna, linha 7-8)

Alun@ 3, por outro lado, julga em termos de Estima Social Negativa (Martin e White op. cit.: 54), modalizando seu julgamento com o uso do termo "normal" (linha 11) e justificando o mesmo com mais uma modalização por meio da escolha do verbo de probabilidade "happen" (acontece, linha 15).

Esse trecho da interação sugere que os alunos que participaram conseguem discutir questões relativas à vida cotidiana, em inglês, por meio da leitura de uma instância do gênero webcomic. Entretanto, quando o contexto se torna mais específico e culturalmente situado, a leitura se prova mais complexa.

$\mathrm{Na}$ segunda postagem, os alunos têm dificuldade em compreender a história, que é uma webcomic humorística de ficção científica. Após explicação sobre os elementos da 
história, dada por mim, os alunos discutiram as perguntas e tiveram mais dificuldade em trazer o tema para sua própria realidade. Na tabela 2, podemos ver como essa dificuldade influencia sua capacidade de comentar criticamente o texto.

Tabela 2: Discussão on-line relacionada à segunda postagem

\begin{tabular}{|l|l|}
\hline Linha & Alun@1 \\
\hline 40 & For me, the text exhibition the teenage that speak slang. That is why, \\
41 & we didn't understand very well the comic. But I understand that the \\
42 & teenager didn't have a good opinion because of the face the another \\
person. It's ok! The teenager must learn in the future.
\end{tabular}

Todos os Alun@s que participaram do debate tentam explicar suas respectivas leituras do texto e como chegaram às suas conclusões. Em outras palavras, o foco para a maioria das postagens foi compreender o texto e sua mensagem, sem a possibilidade de analisá-lo. A única exceção foi a contribuição de Alun@5, que depois da minha intervenção, sinalizou com alta Gradação (“Of course I go back to the past to me to give me many warnings.", linha 61). 
A meu ver, isso teria acontecido principalmente pela falta de contexto: um tópico abordado com referências à "cultura geek", como viagem no tempo e Magic: the gathering. Em conversa com os alunos que participaram, também surgiu a questão da gramática e vocabulário: eles disseram terem focado no tempo verbal (present perfect) que ainda não tinha sido trabalhado e não conseguiram entender o contexto da história.

Em suma, por uma infelicidade na escolha do segundo texto, os alunos tiveram mais dificuldade para compreendê-lo. O contexto de cultura foi muito fora de sua realidade e, casado a isso, a língua se mostrou uma barreira ao entendimento da webcomic.

\section{CONSIDERAÇÕES FINAIS}

Nesse trabalho, busquei analisar a construção de sentido no ambiente on-line como parte da avaliação em um curso de inglês em Niterói, Rio de Janeiro, no qual atuo como professor de Inglês Língua Estrangeira. O trabalho foi conduzido em um período de dois meses durante o segundo semestre de 2016 e consistiu na leitura e discussão on-line do gênero webcomic e subsequente produção de um texto escrito na mesma temática da discussão.

Resultados sugerem que a discussão on-line provê aos estudantes um local de autoria colaborativa e construção de conhecimento, tal qual a sala de aula. $\mathrm{O}$ ambiente virtual é, dessa forma, encarado como um espaço real. Isso indica uma possibilidade de trabalho pedagógico na internet e para fora dela, de forma a permitir inserção da escola no ambiente hipersemiotizado no qual os estudantes já estão inseridos em contextos cotidianos.

Algumas questões, entretanto, emergem nesse cenário: como evitar que a sala de aula se torne o ambiente de polarização encontrado nas redes sociais atualmente? Como compreender o ciberespaço como mais um dos vários locais de construção social frente a parcela da população que não cresceu nesses espaços?

O multiletramento crítico, nesse sentido, deve ser repensado de forma a responder a essas questões e buscar compreender como e se é necessário letrar estudantes para compreender e interagir com textos recontextualizados pelo ciberespaço de forma consciente.

Os estudantes adultos apresentados nesse trabalho, já capazes de interagir e produzir textos com base na leitura do gênero webcomic, conseguem se posicionar criticamente sobre seu conteúdo sem um trabalho prévio com o gênero. Porém, deve ser dada especial atenção ao conhecimento linguístico e cultural do alun@ ao selecionar os textos, com o cuidado de selecionar textos compatíveis com a realidade do grupo. 
Considero que o trabalho que deve ser feito, neste caso, é o de apresentar o aluno ou a aluna a diversos discursos que circulam nesses gêneros e, assim, contribuir para o desenvolvimento de seu senso crítico.

\section{REFERÊNCIAS}

A Softer World Disponível em: http://www.asofterworld.com

BAWARSHI, A. S.; REIFF, M. J. Gênero: história, teoria, pesquisa, ensino. São Paulo: Parábola, 2013

BESSI, A. et al. Users polarization on facebook and youtube. PLOS ONE 11. Disponível em: http://journals.plos.org/plosone/article/file? id=10.1371/journal.pone.0159641\&type=printable

BOHN, H. As exigências da pós-modernidade sobre a pesquisa em Lingüística Aplicada no Brasil. Lingüística Aplicada e contemporaneidade. São Paulo, SP: ALAB, p. 11-23, 2005

CAVAlCANTI, M. Applied linguistics: Brazilian perspectives. AILA review, v. 17, n. 1, p. 23-30, 2004.

DENZIN, N.; LINCOLN, Y. The Sage handbook of qualitative research. Sage, 2005.

FIGUEIREDO, D. C. Leitura e escrita na era digital: considerações críticas para professor@s de língua. Estudos críticos da linguagem e formação de professores/as de línguas: contribuições teórico-metodológicas. 1ed. Campinas SP: Pontes, v. 1, p. 145-166, 2014

FREIRE, P. Pedagogia da Autonomia: saberes necessários à prática educativa. São Paulo: Paz e Terra, 2011

HALLIDAY, M.; MATTHIESSEN, C. An introduction to functional grammar. Routledge, 2014.

HYON, S. Genre in three traditions: Implications for ESL. TESOL quarterly, v. 30, n. 4, p. 693-722, 1996.

KRESS, G.; VAN LEEUWEN, T. Reading images: The grammar of visual design. London: Routledge, 1996.

KUMARAVADIVELU, B. A linguística aplicada na era da globalização. Por uma linguística aplicada indisciplinar. São Paulo: Parábola, p. 129-148, 2006.

LÉVY, P. tradução de Irineu da Costa. Cibercultura. São Paulo: Ed, v. 34, 1999

LIMA, S; COROA, M. Configuração e papel do sistema de avaliatividade no gênero reportagem. Calidoscópio, v. 8, n. 2, p. 127-137, 2010.

MANOVICH, L. The language of new media. MIT press, 2001. 
MARCUSCHI, L. A. Gêneros textuais emergentes no contexto da tecnologia digital. Hipertexto e gêneros digitais. São Paulo: Cortez, p. 15-80, 2010.

MARKHAM, A. N. Internet communication as a tool for qualitative research. Qualitative research: Theory, method and practice, v. 2, 2004.

MARTIN, J. R.; WHITE, P. R. The language of evaluation. London: Palgrave Macmillan, 2003.

Genre and literacy-modeling context in educational linguistics. Annual review of applied linguistics, v. 13, p. 141-172, 1992.

MARTINO, L. M. Teoria das mídias digitais. Editora Vozes Limitada, 2 ed, 2015.

MCCLOUD, S. Reinventando os quadrinhos.São Paulo: M. Books do Brasil Editora Ltda, 2006

MEURER, J. L.; BALOCCO, A. E. A linguística sistêmico-funcional no Brasil: interfaces, agenda e desafios. Anais do SILEL, v. 1, 2009.

MOTTA-ROTH, D.; LOVATO, C. O poder hegemônico da ciência no discurso de popularização científica. Calidoscópio, v. 9, n. 3, p. 251-268, 2011.

NÓBREGA, A; ABREU, A. Vozes argumentativas e posicionamento autoral na produção escrita escolar. Gragoatá, v. 20, n. 38, 2015

OLIVEIRA, L.; CARVALHO, M. A. Fairclough. In. Estudos do Discurso, perspectivas teóricas. São Paulo: Parábola Editorial, p. 275-298, 2013.

PINTO, A. Gêneros discursivos e ensino de língua inglesa. Gêneros Textuais e Ensino. Rio de Janeiro: Editora Parábola, 2010.

POSSENTI, S. Questões para analistas do discurso. Parábola, 2009.

ROJO, R. Letramento (s): práticas de letramento em diferentes contextos. Letramentos múltiplos, escola e inclusão social, 2009.

Saturday Morning Breakfast Cereal Disponível em: http://www.smbc-comics.com

SIGNORINI, I. Bordas e fronteiras entre as escritas grafocêntricas e hipermidiáticas. Linguística aplicada na modernidade recente: festchrift para Antonieta Celani. São Paulo: Parábola, p. 197-209, 2013.

VIAN JR, O. Linguística Sistêmico-Funcional, Linguística Aplicada e Linguística Educacional. MOITA LOPES, LP Linguística Aplicada na modernidade recente. São Paulo: Parábola, 2013. 
. O Sistema de Avaliatividade e a linguagem da avaliação. VIAN JR., O. et al. A linguagem da avaliação em língua portuguesa: estudos sistêmico-funcionais com base no Sistema de Avaliatividade. São Carlos, Pedro \& João Editores, 2010.

XAVIER, A. Leitura Texto e Hipertexto. Hipertexto e gêneros textuais: novas formas de construção de sentido. São Paulo: Cortez, p. 207-220, 2010.

\section{O AUTOR}

Rodrigo Costa dos Santos é Mestre em Estudos da Linguagem pela PUC-Rio. Possui dupla licenciatura em Línguas e Literaturas Portuguesa e Inglesa pela UFF (2015). Ensinou inglês para fins acadêmicos no programa Idiomas sem Fronteiras (2013-2015) e trabalhou como Tutor Online no LwB Online Teacher Development Course do Ministério da Educação (20162017). Atualmente trabalha como professor de inglês no Programa de Línguas Estrangeiras Modernas (Prolem) na UFF. Faz pesquisas em Linguística Aplicada, com ênfase em Linguagem e Tecnologia. Seus interesses de pesquisa envolvem Avaliatividade do Discurso e Mídias Digitais.

E-mail: rodrigo_costa@id.uff.br 


\section{ANEXOS}

\section{Anexo 1: Postagem das Discussões Online}

Hello, people.

This week, we are talking about the story behind a picture

"A Softer World" by E Horne \& J Comeau is a site dedicated to creating fictional stories around their personal pictures.

For this week, discuss the question after reading the text here:

http.//www.asofterworld.com/index.php?id=4

What do you think the story is about?

Do you think the message of the story is positive or negative? Why?

Let's have a nice and healthy discussion!

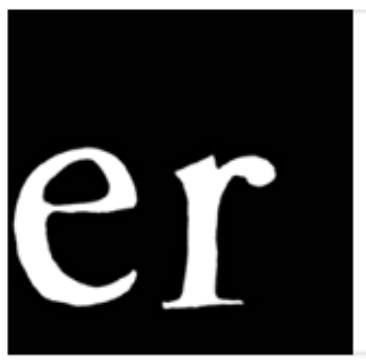

A Softer World was ever Friday

ASOFTERWORID COM

Like $\quad \Rightarrow$ Comment $\Rightarrow$ Share 
Hello,

Read the webcomic here: http://www.smbc-comics.com/comic/time-travel (Don't forget the red button)

Now answer the questions:... See more

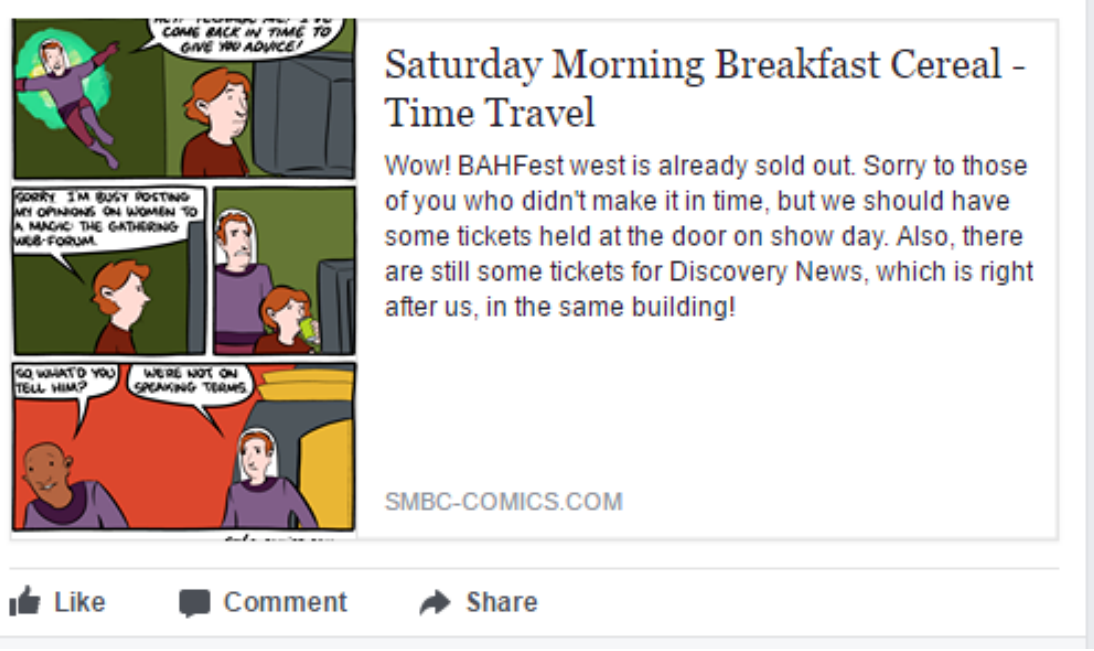


Anexo 2: A Softer World e Saturday Morning Breakfast Club
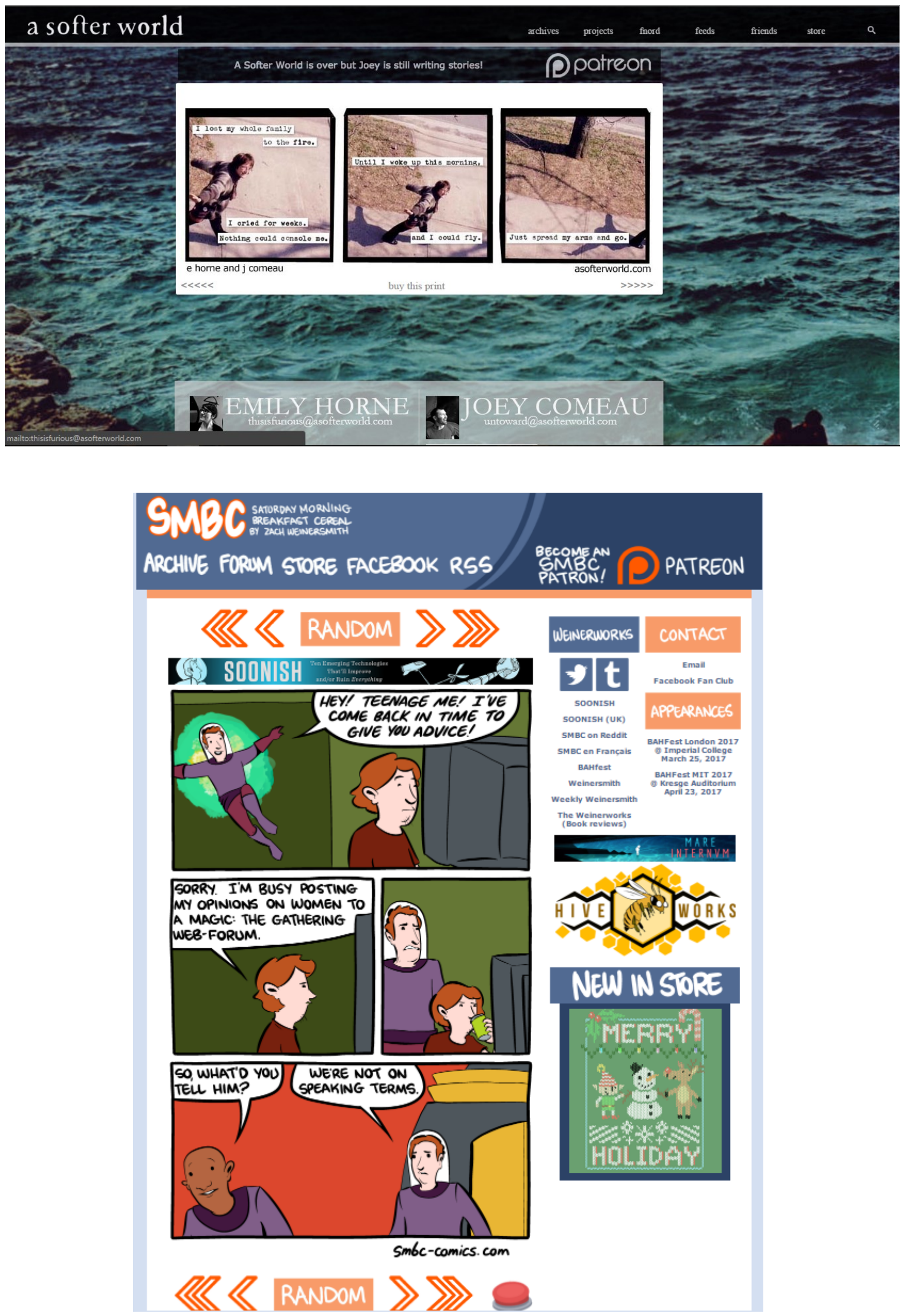